\title{
TESTES DE DIFERENTES MÉTOdOS DE CAPTURA DE IMAGENS DE CÉlULAS ESPERMÁTICAS
}

Luciano Carlos Ribeiro da Silva ${ }^{1}$, Aline Sousa Camargos ${ }^{1,2}$, Matheus Henrique Alves Sousa ${ }^{1}$, Vitor Lemes Silva ${ }^{1}$, Andrea Francisca Araujo ${ }^{1}$, Ana Paula Balduíno Rabelo ${ }^{1}$, Fagner Henrique Dantas Soares ${ }^{1}$, Eunice Oba ${ }^{2}$

${ }^{1}$ Instituto Federal Goiano, Departamentos de Informática e Zootecnia, Morrinhos, GO. ${ }^{2}$ Departamento de Reprodução Animal e Radiologia Veterinária, FMVZ UNESP, Botucatu, SP.

\section{RESUMO}

Objetivou-se testar três métodos de captura de imagem de baixo custo, a fim de viabilizar o futuro uso do software em desenvolvimento. Foram utilizadas 20 amostras de sêmen congelado para confecção das imagens. Uma gota de $10 \mu \mathrm{L}$ de sêmen foi adicionada em lâmina, e essa levada ao microscópio ligado a uma câmera própria de microscópio e com uma câmera digital e um telefone celular com câmera posicionados nas oculares do microscópio por meio de suporte. Foram feitos vídeos de 20 segundos. A partir deles, foram feitas fotos, que o técnico utilizou para fazer a contagem de espermatozóides para comparação do alcance e precisão de cada dispositivo de captura de imagem. Os resultados foram submetidos à análise de variância e Teste de Tukey, a 5\% de significância. O número médio de espermatozoides contados nas imagens diferiram, sendo 145,10 \pm 98,72 para a câmera de microscópio, 17,90 $\pm 11,25$ câmera digital e 407,80 $\pm 299,42$ câmera do celular $(p<0,05)$. Observou-se grande variação do desempenho dos diferentes tipos de captura de imagem, sendo que a câmera do celular obteve o melhor desempenho.

Palavras-chave: Microscópico, CASA, Programas de computador, Espermatozóide, Image Capture

\section{TESTING DIFFERENT APPROACHES FOR IMAGE CAPTURE OF SPERMATIC CELLS}

\begin{abstract}
The objective was to test three methods of low cost image capture, in order to make possible the future use of the software in development. Twenty frozen semen samples were used to make the images. One drop of $10 \mu \mathrm{L}$ of semen was added on a slide, and this was carried under a microscope attached to a microscope camera and with a digital camera and a camera phone positioned in the eyepieces of the microscope by means of a holder. A 20-second videos were made. From them, pictures were taken, which the technician used to do the sperm count to compare the range and accuracy of each image capture device. The results were submitted to analysis of variance and Tukey's test, at $5 \%$ of significance. The mean number of spermatozoa counted in the images differed, being $145.10 \pm 98.72$ for the microscope camera, $17.90 \pm 11.25$ for the digital camera and $407.80 \pm 299.42$ for the cellular camera $(p<0.05)$. It was observed a great variation of the performance of the different types of image capture, being that the camera of the cell obtained the best performance.
\end{abstract}

Keywords: Microscopic, CASA, Computer programs, Sperm, Image Capture 


\section{INTRODUÇÃO}

A tecnologia, comumente aplicada à pecuária, está cada vez mais presente no cotidiano dos rebanhos brasileiros, aliada às técnicas específicas dos sistemas de produção, ela está impulsionando os índices de produtividade dos animais e colaborando para uma pecuária mais eficiente e sustentável. Os avanços são bastante visíveis, com uso de ferramentas simples de manejo e tecnologia (ABIEC, 2014).

Os programas computadorizados para a avaliação espermática podem ser mais objetivos e imprimir maior repetibilidade às observações do que a habilidade do técnico no campo em identificar padrões de motilidade espermática, sendo a analise computadorizada (ComputerAssisted Sperm Analysis - CASA) uma das mais utilizadas. Análises do tipo (CASA) permitem uma avaliação precisa e acurada dos espermatozóides com alto grau de objetividade, podendo aperfeiçoar então o processo de avaliação de sêmen (Arruda, 2000; Matos, 2008).

Um dos maiores desafios para a análise da célula espermática, o espermatozoide, é a escolha e padronização do melhor meio de captura de imagem. Deste modo, este trabalho teve por objetivo testar três métodos de captura de imagem de baixo custo, a fim de viabilizar o futuro uso do software em desenvolvimento.

\section{MATERIAL E MÉTODOS}

Foram utilizadas 20 amostras de sêmen congelado para confecção das imagens. Cada amostra de sêmen bovino, em palheta de $0,5 \mathrm{~mL}$, foi retirada do botijão com nitrogênio líquido (MVE20, CRV Lagoa) e colocada em banho maria a 37ㅇ C por 30 segundos para descongelar. Em seguida, a palheta foi cortada e colocada em um microtubo de $2 \mathrm{~mL}$, sobre mesa aquecedora, para escoamento do sêmen.

Com o auxílio de uma micropipeta, uma gota de $10 \mu \mathrm{L}$ foi adicionada sobre uma lâmina e coberta por uma lamínula para microscopia. Os microscópios foram devidamente ajustados para a observação da amostra e foram travados, de tal forma que as configurações concernentes à microscopia não mais determinassem a qualidade da imagem a ser capturada. No primeiro microscópio foi utilizado uma objetiva digital (1.3MP, Coleman), como pode ser visto na Figura 1; no segundo microscópio foi acoplado uma câmera digital de uso doméstico (Coolpix, L340, Nikon), como pode ser visto na Figura 2; por fim, no terceiro microscópio foi acoplado um smartphone (iPhone 5C, Apple), como pode ser visto na Figura 3.

Figura 1. Microscópio 1, montado com sua própria câmera digital acoplada.

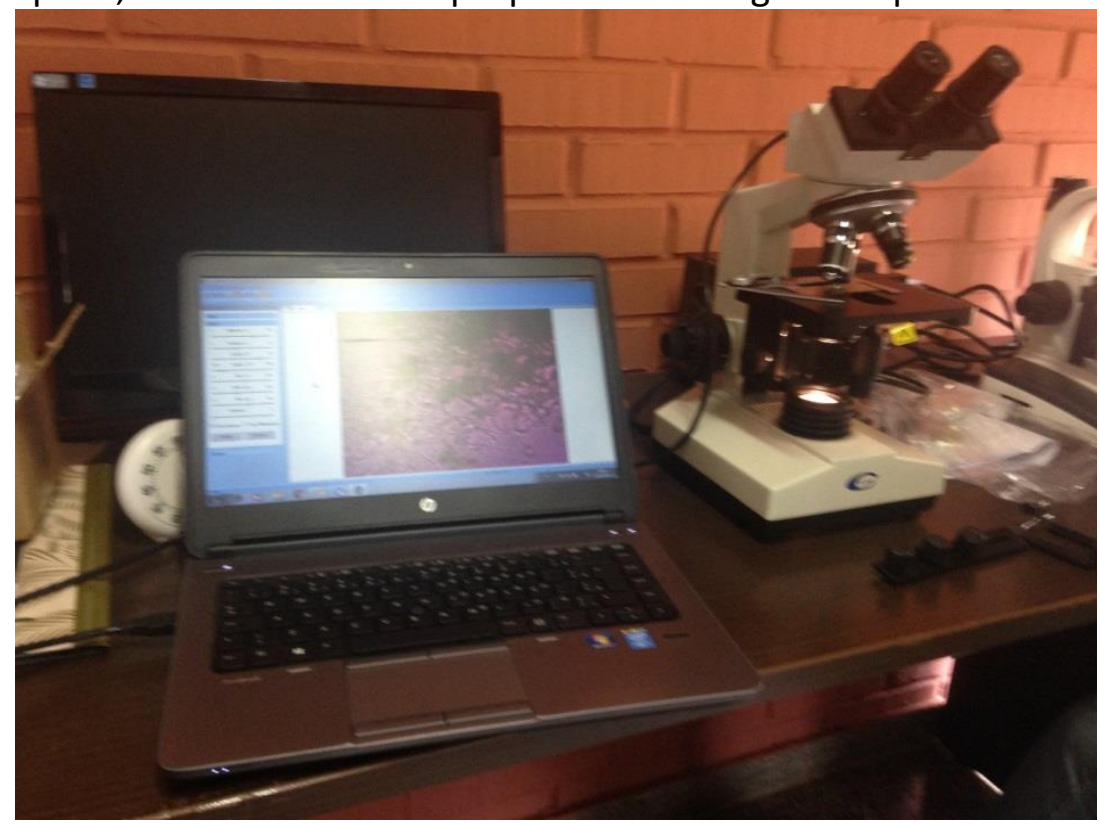


Figura 2. Microscópio 2, montado com uma câmera digital doméstica (Coolpix, L340, Nikon).

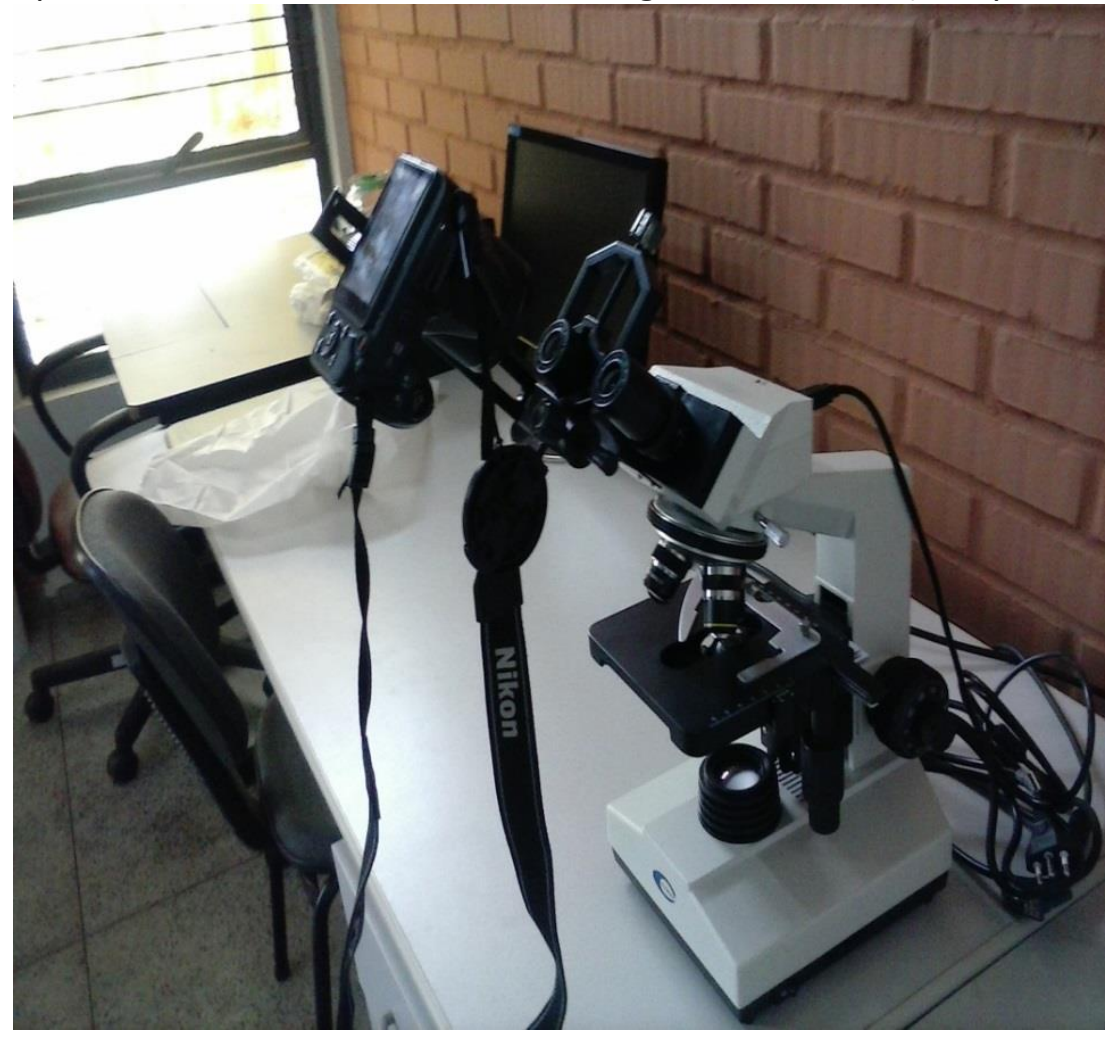

Figura 3. Microscópio 3, montado com um smartphone (iPhone 5C, Apple).

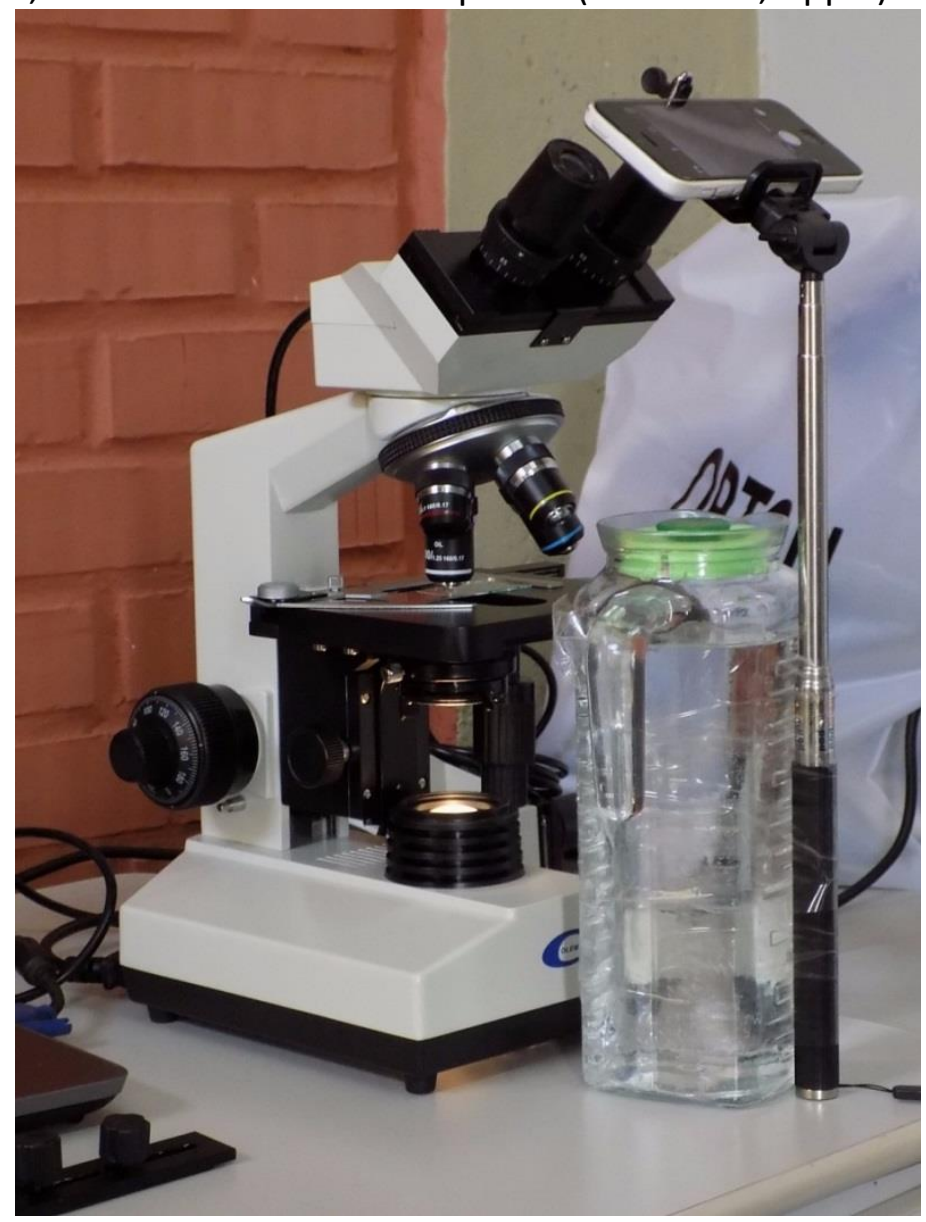


Foram feitos vídeos de aproximadamente 20 segundos com os dispositivos para cada amostra. A partir deles, foram feitas fotos aos 10 segundos de cada vídeo. Um técnico realizou a contagem das células espermáticas nas fotos para comparação do alcance e precisão de cada dispositivo de captura de imagem.

Os resultados foram submetidos à análise de variância e Teste de Tukey, ao nível de significância de $5 \%$.

\section{RESULTADOS E DISCUSSÃO}

O número médio de espermatozoides contados na imagem de cada amostra foi $145,10 \pm$ 101,28 para a câmera própria de microscópio (Coleman), 17,90 $\pm 11,54$ para a câmera digital (Nikon) e 407,80 $\pm 307,20$ para a câmera do telefone celular (iPhone). Esta última diferenciou dos demais $(p<0,05)$.

Figura 4. Métodos de captura de imagem de amostra de sêmen bovino. 1 - Foto realizada com câmera própria para microscópio (Coleman). 2 - Foto realizada com câmera digital (Nikon). 3 Foto realizada com câmera de telefone celular (iPhone).

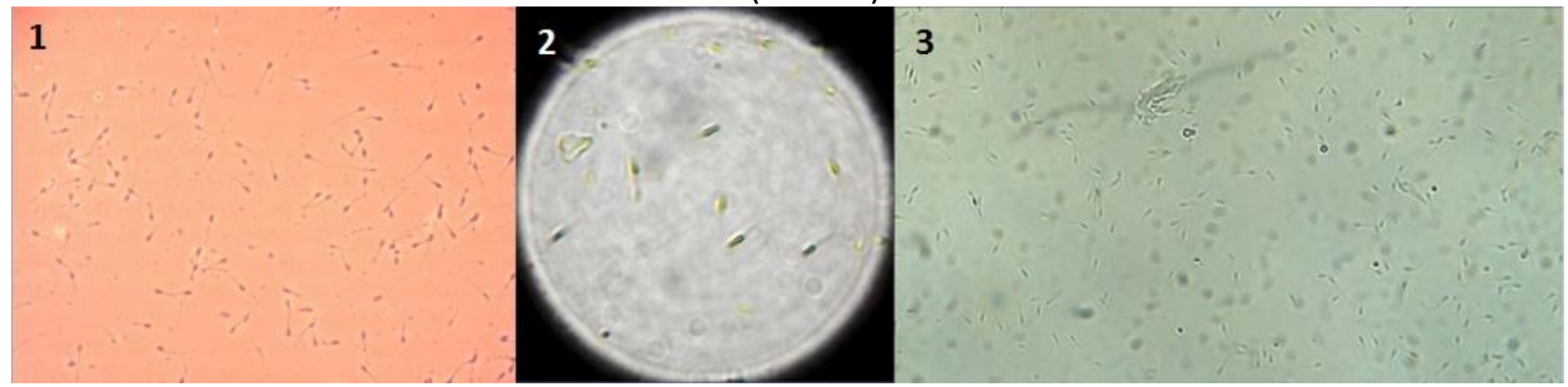

Apensar de não ter sido um problema no primeiro microscópio (Figura 1), pois contatava com uma lente digital própria na mesma posição de uma de suas oculares, o posicionamento, o foco, o balanço de branco, o valor de exposição e a estabilização da câmera digital doméstica (Figura 2) e do smartphone (Figura 3) exigiram cuidados extras. Contudo, uma vez firmemente posicionados, tanto a câmera digital doméstica quanto o smartphone conseguiram realizar o autofoco com base na imagem projetada pela objetiva original dos microscópios com precisão aceitável. Todavia, como pode ser observado na Figura 4, a imagem com melhor foco é a 1, capturada pela objetiva própria do microscópio.

Não obstante, como pode ser facilmente observado na Figura 4, tanto o balanço de branco automático quanto a exposição automática tiveram variações consideráveis. Na questão do balanço de branco, nota-se que a Imagem 1 da Figura 4 apresenta um fundo alaranjado; a Imagem 3 apresenta um fundo tendendo para o verde e a Imagem 2, com o melhor batimento de branco das três configurações, com o fundo acinzentado.

Entretanto, a variação mais preocupante é o valor de exposição. Isso pois uma filmagem sub exposta pode ocultar os gametas nas regiões mais escuras e uma filmagem superexposta pode gerar estouros de branco nas regiões mais claras, também obsfuscando as células presentes nessas regiões. Como o objetivo da era capturar as imagens utilizando o processo mais simples possível, ou seja, com menor intervenção nas configurações dos equipamentos de captura, podese notar, como já dito, consideráveis variações de captura.

Em relação ao campo de visão, que tem influência direta sobre a área da imagem capturada, percebe-se que maior abrangência foi obtida pelo smartphone. Já em relação a qualidade do foco, o melhor resultado foi obtido pela câmera do microscópio, que também se beneficiou do seu firme sistema de acoplamento interno, evitando os tremores da filmagem, 
como ocorreram nas outras duas capturas, e, de forma mais evidente, no instante de interação com o dispositivo para iniciar e parar a gravação.

O suporte da câmera específico para o microscópio pode ser encontrado em loja virtual na internet. $O$ suporte para o telefone celular é de uso genérico e foi adaptado para este uso, tendo o menor custo.

Supõe-se que todos os tipos de imagens poderão ser utilizados pelo software de análise espermática. No entanto, por conta das variações apresentadas, deverá ser realizada uma configuração no software com base no sistema de captura, de tal forma que os erros de balanço de branco e exposição sejam minimizados. Se o software se propor a fazer uma contagem absoluta, deve ser observado as regiões de alta e baixa exposição. Caso seja feito uma contagem estatística, recomenda-se realizar um recorte da região central da filmagem, reduzindo assim os problemas com vinhetas nas regiões periféricas do vídeo.

É preponderante asseverar que o software deverá utilizar meios automatizados para definir a relação pixel/esperma, pois a distância focal, que influencia no campo de visão, também irá definir quantos pixels, em média, uma célula ocupa na imagem. Essa diferença pode ser facilmente notada no tamanho do gameta obtido pela Imagem 2 e nas demais imagens da Figura 4.

\section{CONCLUSÃO}

Há uma importante variação do desempenho dos diferentes tipos de captura de imagem, sendo que a câmera do microscópio obteve o melhor desempenho. Ajustes manuais podem diminuir a diferença na captura, mas definitivamente terão impacto na usabilidade dos métodos, pois exigirá do usuário maiores conhecimentos na teoria fotográfica e no domínio das configurações internas dos dispositivos.

De qualquer modo, todas as diferenças podem ser contornadas pelo software de análise que, nesse caso, terá maior complexidade algorítmica por ter que tratar todas essas diferenças. Destaca-se aqui que, especificamente nesse quesito, um hardware especializado, como um CASA, leva vantagem, pois a captura da imagem tende a ser mais controlada e constante.

\section{REFERÊNCIAS}

ABIEC, Associação Brasileira de Indústrias Exportadoras de Carne. Estatísticas do ano de 2013. ABIEC, 2014.

ARRUDA, R. P. Avaliação dos efeitos de diluidores e crioprotetores para o espermatozóide eqüino pelo uso de microscopia de epifluorescência, citometria de fluxo, análises computadorizadas da motilidade (CASA) e da morfometria (ASMA). Tese (Livre Docência) Faculdade de Medicina Veterinária e Zootecnia, Universidade São Paulo. São Paulo, SP, 2000. 121p.

COX JF, ALFARO V, MONTENEGRO V, RODRIGUEZ-MARTINEZ H. Computer-assisted analysis of sperm motion in goats and its relationship with sperm migration in cervical mucus. Theriogenology, v. 66, p. 860-867, 2006. https://doi.org/10.1016/i.theriogenology.2006.01.062

MATOS D.L, ARAÚJO A.A, ROBERTO I.G, TONIOLLI R. Análise computadorizada de espermatozóides: revisão de literatura. Computer-Assisted Sperm Analysis (CASA): a review. Revista Brasileira de Reprodução Animal, v.32, n. 4, p. 225-232, 2008. 